\title{
Cold Urticaria: A Rare Manifestation of Lymphoma
}

\author{
Sadan Soyyigita, d, Zeynep Celebi Sozener ${ }^{\mathrm{a}}$, Erden Atilla ${ }^{\mathrm{b}}$, Aylin Okcu Heper ${ }^{\mathrm{c}}$, Gulsah Kaygusuz ${ }^{\mathrm{c}}$, \\ Betul Ayse Sin ${ }^{\mathrm{a}}$
}

\begin{abstract}
Cold urticaria $(\mathrm{CU})$ is characterized by the rapid onset of pruritus, erythema, and swelling after exposure to cold stimulus. CU can be classified into acquired and familial disorders. Acquired cold urticaria (ACU) is sometimes associated with serious underlying diseases, such as malignancies, systemic leukocytoclastic vasculitis and infectious diseases. A 55-year-old man was admitted to our hospital with 1-year history of urticarial rash, itching and angioedema on the parts of his body after cold exposure. He had no family history. Diagnosis was confirmed by applying ice cube test. Marginal zone B-cell lymphoma has not yet been reported as a cause of secondary ACU. Here, we report a patient with secondary ACU which was also diagnosed as marginal zone B-cell lymphoma.
\end{abstract}

Keywords: Cold urticaria; Lymphoma; Marginal zone B-cell lymphoma; Acquired secondary cold urticaria; Leukocytoclastic vasculitis; Cryoglobulinemia

\section{Introduction}

Cold urticaria (CU) accounts for approximately $3 \%$ of all cases of chronic urticaria [1]. CU is very rare and generally benign. The disease may be classified into acquired and familial disorders. The acquired types are further categorized as primary acquired, secondary acquired, and atypical acquired [2]. Secondary acquired cold urticaria (ACU) occurs most frequently with primary and secondary cryoglobulinemia, e.g. secondary

Manuscript accepted for publication May 06, 2014

aDivision of Immunology and Allergic Diseases, Department of Chest Diseases, Faculty of Medicine, Ankara University, Ankara, Turkey

${ }^{b}$ Division of Hematology, Department of Internal Medicine, Faculty of Medicine, Ankara University, Ankara, Turkey

'Department of Pathology, Faculty of Medicine, Ankara University, Ankara, Turkey

${ }^{\mathrm{d} C}$ Corresponding Author: Sadan Soyyigit, Division of Immunology and Allergy Diseases, Department of Chest Diseases, School of Medicine, Ankara University, Ankara 06620, Turkey. Email: sadansoyyigit@gmail.com

doi: http://dx.doi.org/10.14740/jmc1803w to chronic lymphocytic leukemia, lymphosarcoma, leukocytoclastic vasculitis, hepatitis $\mathrm{C}$ virus infection and angioimmunoblastic lymphadenopathy $[2,3]$. The specific association of $\mathrm{CU}$ and marginal zone B-cell lymphoma has not been reported. Therefore, we want to present a patient with $\mathrm{CU}$ which was diagnosed as marginal zone B-cell lymphoma.

\section{Case Report}

A 55-year-old man was admitted to our hospital with a 1-year history of urticarial rash, itching and angioedema on the parts of his body after exposure to cold. He also defined complaints of dyspnea especially in the upper airways and cramps in the stomach by drinking cold water/beverages. There were no associated constitutional symptoms, such as fever or arthralgias. He had no family history of atopy and CU. His physical examination was normal. An ice cube test that applied to on right forearm skin for 5 min resulted in the development of a wheal and angioedema $(6 \times 5 \mathrm{~mm})$ within $4 \mathrm{~min}$ of removal and persisted for $1 \mathrm{~h}$. CU diagnosis was confirmed by applying ice cube test (Fig. 1). We observed purpuric lesions on the lower extremities of the patient after exposure to cold weather. His hemoglobin and hematocrit values were $12 \mathrm{~g} / \mathrm{dL}$ and $35.6 \%$, respectively. Biochemical screening, erythrocyte sedimentation rate, thyroid function tests, anti-thyroid autoantibodies, anti-human immunodeficiency virus (HIV) antibody, immunoglobulin (Ig) IgA, IgM, ANA, anti-ds-DNA, lupus anticoagulant, anticardiolipin antibody, antineutrophil cytoplasmic antibodies, anti-Ro/SSA, anti-La/SSB, rheumatoid factor, anticitrullinated protein antibodies, serum folate, vitamin B12, ferritin and iron level, $\mathrm{C} 1$ esterase inhibitor, $\mathrm{Clq}$, basal tryptase level, urine tests and peripheral blood smear were normal. There were no parasites in the stool sample. Sputum, throat, blood and urine cultures were negative. Total IgE level was $50.6 \mathrm{kU} / \mathrm{L}$, and inhalant allergens mix specific IgE (UNI-CAP 100, Phadia, Uppsala, Sweden) was also negative. His hepatitis $\mathrm{B}$ and $\mathrm{C}$ panel investigations were negative. C-reactive protein was high $(19.7 \mathrm{mg} / \mathrm{mL}$ (normal range: $0-3 \mathrm{mg} / \mathrm{mL}$ )). Serum complement levels were low (C3: $0.864 \mathrm{~g} / \mathrm{L}$ (normal range: $0.9-1.8 \mathrm{~g} / \mathrm{L}$ ); C4: $0.0179 \mathrm{~g} / \mathrm{L}$ (normal range: $0.1-0.4$ $\mathrm{g} / \mathrm{L})$ ). Serum cryoglobulin and direct coombs tests were positive. Serum IgG level was low (IgG: $5.6 \mathrm{~g} / \mathrm{L}$ (normal range: 7 - $16 \mathrm{~g} / \mathrm{L})$ ). Serum protein electrophoresis demonstrated a poly- 


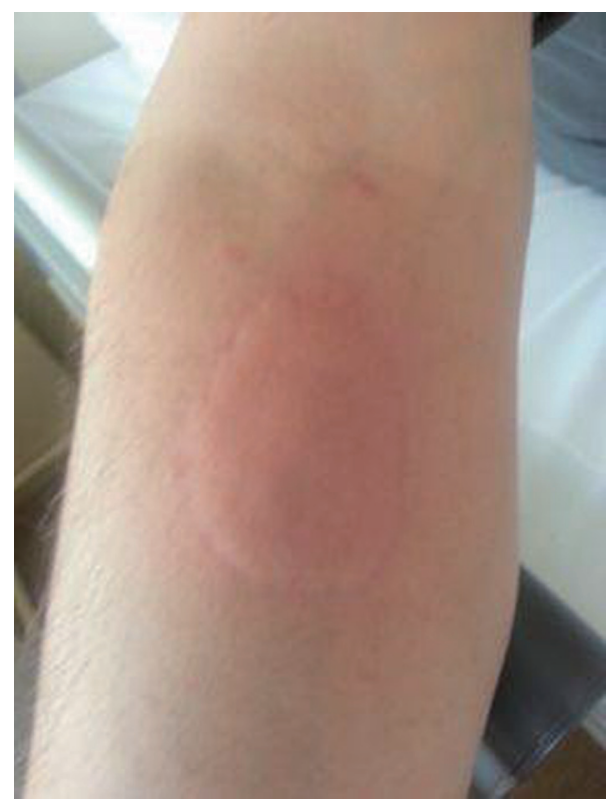

Figure 1. The appearance of skin after applying ice cube test.

clonal pattern of hypogammaglobulinemia (gamma globulin level: 9.3\% (normal range: 11.1-18.8\%)). Serum kappa level was low $(1.65 \mathrm{~g} / \mathrm{L}$ (normal range: 1.7 - $3.7 \mathrm{~g} / \mathrm{L})$ ), urine kappa level was high (14.6 mg/L (normal range: $0.7-1 \mathrm{mg} / \mathrm{L}$ )), and serum and urine free lambda were normal. Beta-2 microglobulin was high ((4.49 mg/L (normal range: $1.09-2.53 \mathrm{mg} / \mathrm{L}))$. A skin biopsy was performed from the lesion which was induced with the cold test. Leukocytoclastic vasculitis was diagnosed by the examination of the pathologic specimen (Fig. 2). A thoracoabdominal computed tomography $(\mathrm{CT})$ revealed a left supraclavicular mass $(33 \times 18 \mathrm{~mm})$ that partially surrounded the artery in the upper mediastinum and a soft tissue mass (67 $\times 30 \mathrm{~mm}$ ) which surrounded inferior vena cava and supressed aorta at retroperitoneal region. There were enlarged lymph nodes, adjacent to the supraclavicular mass, in both supraclavicular, periaortic, paratracheal, subcarineal, right hilar, both internal mammarian chain region and many pathologic lymph nodes in left gastric, periportal, aortakaval, para-aortic and right inguinal lymphatic region and splenomegaly. The patient was scheduled for diagnostic laparoscopy. Pathological lymph nodes were excised. Microscopically, the lymph node was infiltrated by a tumor in a nodular pattern composed of small lymphoid cells surrounding the germinal centers (Fig. 3A, B). Immunohistochemistry was performed on tissue sections by using Ventana automated immunostainer. The neoplastic cells were positive for CD20, BCL2 and kappa light chain (Fig. 3C, D). These findings were consistent with marginal zone B-cell lymphoma. The bone marrow biopsy showed nodular paratrabecular lymphoid infiltration expressing CD20 and kappa light chain (Fig. 3E-H).

The patient was referred to hematology clinic with a diagnosis of stage 4 marginal zone B-cell lymphoma. After four cycles of chemotherapy, our patient's cold urticarial symptoms and skin lesions were completely improved as well as disappearance of enlarged lymp nodes in the CT.

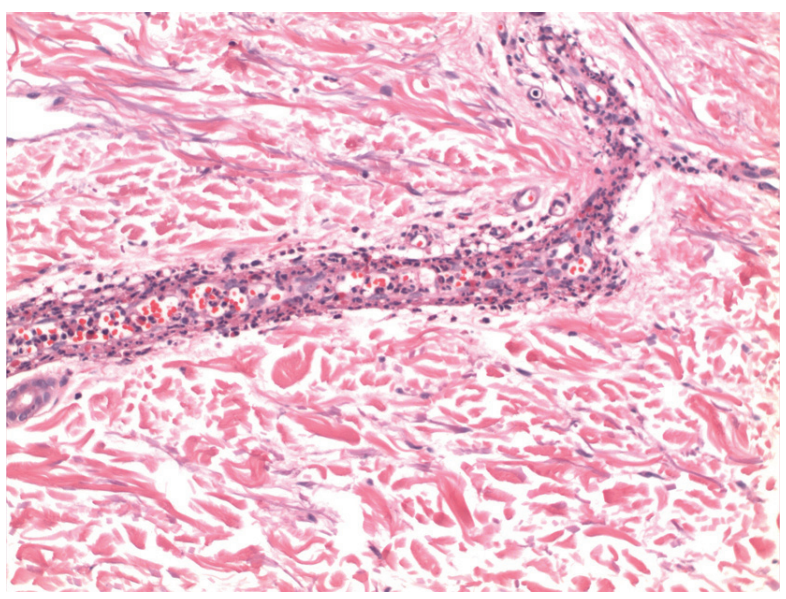

Figure 2. Skin biopsy taken from lesion showed evidence of leukocytoclastic vasculitis by light microscopy. There is a mild neutrophilic infiltrate in the wall of small vessel located in the superficial dermis. Also mild congestion and leukocytoclasis is also present. H\&E, $\times 200$.

\section{Discussion}

The exact incidence of the $\mathrm{CU}$ is unknown, but of all the cases, over $90 \%$ are classified as idiopathic [4]. Although ACU is usually considered benign, several concerns should be addressed in patients with these disorders [2]. The incidence of secondary ACU associated with cryoglobulinemia is low. Approximately $3-4 \%$ of all cryoglobulinemias are associated with ACU [3]. Type I cryoglobulins are single monoclonal immunoglobulins (IgG) always linked to B-cell lymphoproliferative disorders $[5,6]$. These monoclonal proteins can form cold-induced aggregates that may mediate inflammatory vasculitis, which is characterized by cold-induced symptoms. Serum complement measurements in patients with secondary ACU and IgG cryoglobulinemia revealed decreased levels of classic and alternative complement components. IgG cryoglobulins may have been responsible for complement activation, release of $\mathrm{C} 5 \mathrm{a}$ and $\mathrm{C} 3 \mathrm{a}$, and degranulation of mast cells. CU cryoglobulins could represent IgG anti-IgE autoantibodies that react with $\operatorname{IgE}$ attached to mast cells. Cold temperature may favor the interaction of $\operatorname{IgG}$ anti-IgE autoantibodies to IgE attached to mast cells, causing mediator release [7].

Autoimmune manifestations also occur frequently in the course of lymphoproliferative malignancies. They may sometimes be the first sign of the malignancy [8]. Most of the organs can be targeted by an immune process due to the lymphoproliferative diseases. They include skin diseases (paraneoplastic pemphigus, vasculitis, urticaria, peripheral and central nervous system involvement (polyneuropathy, multifocal neuropathy), hematological manifestations (immune cytopenia, acquired bleeding disorders), rheumatologic diseases (arthritis, systemic vasculitis, myositis) and renal lesion (cryoglobulinemia, glomerulopathies)) [9]. Autoimmune manifestations are observed in all lymphoma subtypes and seem particularly prevalent in marginal zone lymphoma and T-cell lymphoma [10].

We found positive ice cube test in our patient. His clinical manifestations supporting secondary ACU with cryoglo- 

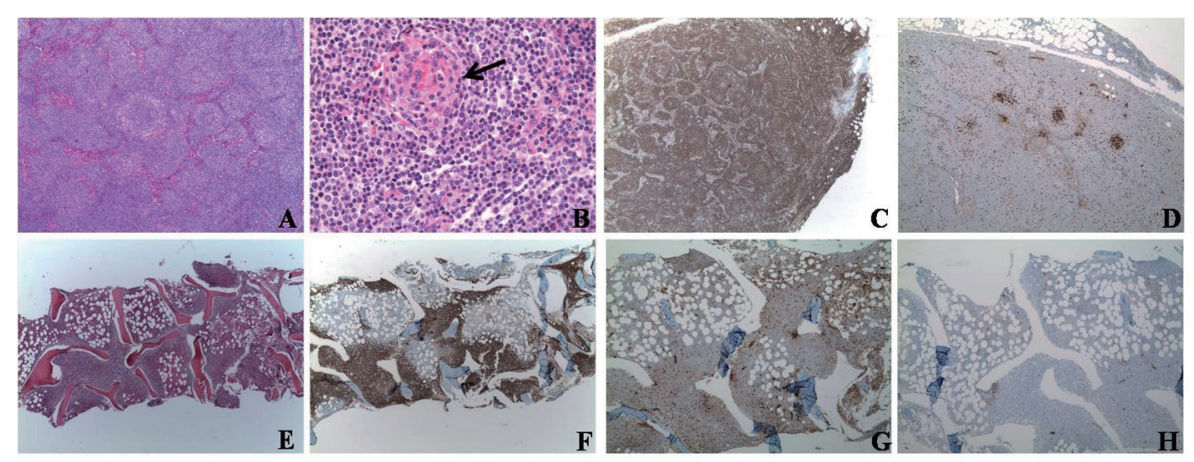

Figure 3. (A, B) The lymph node excision showed atypical lymphoid infiltration (H\&E, $\times 40, \times 400)$. (C, D) Immunohistochemically, the neoplastic cells were positive for CD20 and kappa light chain $(\times 25, \times 40)$. (E) Paratrabecular nodular infiltration was seen in the bone marrow $(\mathrm{H} \& \mathrm{E}, \times 25) .(\mathrm{F}, \mathrm{G}, \mathrm{H})$ The lymphoid cells expressed CD20 and kappa light chain; lambda was negative $(\times 25, \times 40, \times 40)$.

bulinemia consisted of purpuric lesions especially involving lower extremities after cold exposure. He was anemic, his Creactive protein was elevated, and serum $\mathrm{C} 3$ and $\mathrm{C} 4$ complement levels were decreased. He had type 1 cryoglobulinemia, positive direct coombs test. His beta-2 microglobulin was also elevated and polyclonal pattern of hypogammaglobulinemia was shown in serum protein electrophoresis. Leukocytoclastic vasculitis was confirmed with skin biopsy. Thoraco-abdominal CT findings revealed pathologic enlargement of the lymph nodes. The patient was diagnosed as a case of marginal zone B-cell lymphoma.

This observation suggests a possible association and reminds us that patients with unexplained CU may have serious underlying disease. Therefore, we believe that they should be submitted to additional investigations. In conclusion, $\mathrm{CU}$ cases should be evaluated more carefully with regard to unusual disorders.

\section{Conflict of Interest}

As per our conflict of interest declaration, we report that there is no potential conflict of interest.

\section{References}

1. Brodska P, Schmid-Grendelmeier P. Treatment of severe cold contact urticaria with omalizumab: case reports. Case Rep Dermatol. 2012;4(3):275-280.
2. Wanderer AA, Hoffman HM. The spectrum of acquired and familial cold-induced urticaria/urticaria-like syndromes. Immunol Allergy Clin North Am. 2004;24(2):259-286, vii.

3. Siebenhaar F, Weller K, Mlynek A, Magerl M, Altrichter S, Vieira Dos Santos R, Maurer M, et al. Acquired cold urticaria: clinical picture and update on diagnosis and treatment. Clin Exp Dermatol. 2007;32(3):241-245.

4. Koay J, Jones D, Duvic M. Cold urticaria in a patient with mycosis fungoides. J Am Acad Dermatol. 2002;47(4):608610.

5. Takada S, Shimizu T, Hadano Y, Matsumoto K, Kataoka Y, Arima Y, Inoue T, et al. Cryoglobulinemia (review). Mol Med Rep. 2012;6(1):3-8.

6. Terrier B, Cacoub P. Cryoglobulinemia vasculitis: an update. Curr Opin Rheumatol. 2013;25(1):10-18.

7. Payet J, Livartowski J, Kavian N, Chandesris O, Dupin N, Wallet N, Karras A, et al. Type I cryoglobulinemia in multiple myeloma, a rare entity: analysis of clinical and biological characteristics of seven cases and review of the literature. Leuk Lymphoma. 2013;54(4):767-777.

8. Koumati E, Palassopoulou M, Matsouka P, Polyzos A, Dalekos GN, Zachou K. Multiple autoimmune propensity and B-non-hodgkin lymphoma: cause or effect? Autoimmune Dis. 2011;2011:841325.

9. Jardin F, Levesque H, Tilly H. [Auto-immune manifestations in Non-Hodgkin's lymphoma]. Rev Med Interne. 2005;26(7):557-571.

10. Jardin F. Development of autoimmunity in lymphoma. Expert Rev Clin Immunol. 2008;4(2):247-266. 